\title{
Pemfokusan Citra Radar untuk Hasil Pemodelan Radar Penembus Permukaan menggunakan Algoritma Migrasi Jarak
}

\author{
AZIZAH' ${ }^{1}$, ERSHAD JUNUS AMIN ${ }^{2}$ \\ 1 Universitas Telkom \\ 2 Institut Teknologi Bandung \\ Email: azizah@telkomuniversity.ac.id
}

\begin{abstract}
ABSTRAK
Citra Radar Penembus Permukaan (GPR) memberikan gambaran tentang objek dalam bentuk kurva hiperbola. Kurva hiperbola ini memiliki resolusi yang rendah sehingga sulit untuk menganalisis lokasi objek yang sebenarnya. Oleh karena itu diperlukan proses untuk membuat citra menjadi lebih fokus. Proses ini disebut transformasi atau migrasi. Salah satu algoritma migrasi adalah algoritma migrasi jarak. Terdapat beberapa langkah yang dilakukan dalam penelitian ini. Pertama, pemodelan GPR dilakukan menggunakan perangkat lunak. Kemudian, algoritma migrasi jarak diimplementasikan untuk data hasil pemodelan. Terakhir, dilakukan analisis hasil yang didapat. Informasi jumlah dan lokasi objek didapatkan dari citra hasil migrasi ini dengan persentase kesalahan untuk pada sumbu $x$ sebesar $4 \%$ untuk 1 objek, $17 \%$ untuk 2 objek, dan $4 \%$ untuk 3 objek. Sedangkan persentase kesalahan pada sumbu y sebesar 2\% untuk 1 objek, 3\% untuk 2 objek, dan $8 \%$ untuk 3 objek.
\end{abstract}

Kata kunci: GPR, migrasi, algoritma, migrasi jarak, fokus,

\begin{abstract}
Ground Penetrating Radar (GPR) image give description about object in hyperbolic curve. This hyperbolic curve has low resolution so it is too difficult to analysis the actual object position. Therefore, we need a process can make the image more focus. This process usually called transformation or migration. One of them is range migration algorithm. There are several steps in this reseacrh. First, GPR modelling done using software. Next, range migration algorithm is implemented for the data result from simulation. Last, the result are analyzed. The information about the number and object position is obtained from the image in this migration process with margin error in $x$-axis are $4 \%$ for 1 object, $17 \%$ for 2 object, and $4 \%$ for 3 object. On the other side, margin error in $y$-axis are $2 \%$ for 1 object, $4 \%$ for 2 object, and $8 \%$ for 3 object.
\end{abstract}

Keywords: GPR, migration, algorithm, range migration, focus 
Pemfokusan Citra Radar untuk Hasil Pemodelan Radar Penembus Permukaan menggunakan Algoritma Migrasi Jarak

\section{PENDAHULUAN}

Teknologi Ground Penetrating Radar (GPR) yang sudah banyak dimanfaatkan untuk aplikasi tertentu menuntut adanya perkembangan untuk memberikan hasil yang optimal. Perkembangan banyak dilakukan dari sisi perangkat keras ataupun perangkat lunak. Salah satu yang diperlukan dari sisi perangkat keras adalah bagian pengolahan sinyal radar tersebut.

Perkembangan pengolahan sinyal radar terus dilakukan untuk meningkatkan hasil dari citra radar. Keluaran dari GPR bisa ditampilkan dalam bentuk 2 dimensi. Penelitian sebelumnya yang telah dilakukan di bidang GPR adalah mengolah citra GPR menjadi bentuk tiga dimensi. Hal ini dilakukan untuk mengetahui koordinat dan kedalaman dari suatu objek (Azizah, dkk, 2011). Citra yang dihasilkan GPR berupa kurva hiperbola. Kurva tersebut menunjukkan adanya objek yang tersimpan di bawah permukaan tetapi belum menunukkan posisi yang jelas dari objek tersebut. Oleh karena itu, terdapat proses yang diperlukan untuk memfokuskan citra tersebut sehingga bisa didapatkan posisi objek yang lebih presisi. Proses ini disebut migrasi atau transformasi.

Penelitian ini bertujuan untuk melakukan perbaikan terhadap citra tersebut dengan menggunakan algoritma pemfokusan atau algoritma migrasi. Citra yang diolah pada penelitian ini dibatasi hanya dalam bentuk 2 dimensi. Beberapa algoritma migrasi dilakukan untuk membuat citra menjadi lebih fokus, diantaranya adalah metode Hyperbolic Summation, Kirchoff Migration, Frequency-wavenumber Migration, Range Migration Algorithm (Ozdemir, dkk, 2012). Range Migration Algorithm atau algoritma migrasi jarak yang akan digunakan untuk penelitian ini.

\subsection{Radar Penembus Permukaan}

GPR merupakan salah satu teknologi radar yang sudah banyak dikenal pada zaman sekarang ini. GPR adalah radar yang digunakan untuk mendeteksi objek yang tertimbun di dalam suatu medium. Prinsip kerjanya dengan memanfaatkan gelombang elektromagnetik yang dikirimkan kemudian dipantulkan karena mengenai objek tertentu. Hasil pantulan ini yang kemudian direkam. GPR digunakan pada pita gelombang mikro, yaitu pada frekuensi UHF/VHF dari spektrum radio. GPR mengumpulkan data yang cukup kompleks. Data GPR dikumpulkan dalam straight profiles, yang disebut radargramm. GPR bisa digunakan untuk berbagai keperluan, diantaranya untuk aplikasi teknik sipil, melihat jembatan, mendeteksi bebatuan yang ada di dalam tanah, dan lain-lain. Data GPR dinyatakan dalam Persamaan 1.

$$
y(n)=\sum_{k=-\infty}^{\infty} x(k) x(n-k)
$$

\subsubsection{Prinsip Kerja}

GPR memanfaatkan gelombang elektromagnetik yang dikirimkan ke suatu permukaan tanah. Gelombang ini menembus ke permukaan tanah. Antena pengirim menghasilkan sinyal pulsa yang selanjutnya akan dikirimkan seperti yang ditunjukkan pada Gambar 1. Kemudian di antena penerima ditangkap dan akan diproses selanjutnya.

Hasil dari antena penerima akan dianalisis dengan menggunakan teori propagasi gelombang elektromagnetik satu dimensi. Dengan ini menunjukkan bahwa energi yang dikeluarkan ada 
yang sebagian dipantulkan dan ada yang diserap. Gelombang yang dipantulkan adalah gelombang yang mengenai objek tertentu.

Persamaan umum gelombang datar dituliskan pada Persamaan 2 dan 3.

$$
\begin{aligned}
& E(x, t)=A e^{j\left(\omega t-\beta x+\theta_{r}\right)} \\
& \beta=\omega \sqrt{\mu_{0} \epsilon_{0} \epsilon_{r}}
\end{aligned}
$$

Koefisien refleksi dapat dihitung dengan menggunakan Persamaan 4.

$$
\Gamma=\frac{\eta_{2}-\eta_{1}}{\eta_{2}+\eta_{1}}
$$

Sehingga dapat diketahui persamaan gelombang datar yang dipantulkan (untuk bagian real nya saja) didapatkan melalui Persamaan 5.

$$
E(x, t)=|\Gamma| A \cos \left(w t+\beta_{0} x+\theta_{r}\right)
$$

$\theta_{\mathrm{r}}$ menunjukkan fasa awal dari gelombang. $\beta$ adalah bilangan propagasi.

Dengan ini menunjukkan bahwa energi yang dikeluarkan ada yang sebagian dipantulkan dan ada yang diserap. Gelombang yang dipantulkan adalah gelombang yang mengenai objek tertentu. Yang membedakan objeknya bisa dilihat dari kekuatan daya pantulnya. Gelombang yang mengenai objek yang bersifat metal akan memantulkan gelombang dengan kekuatan daya yang besar karena benda yang bersifat metal memiliki nilai permitivitas yang tinggi. Nilai permitivitas yang tinggi ini juga menunjukkan kemampuan bahan tersebut untuk mengalirkan medan listrik. Sedangkan gelombang yang mengenai objek yang non-metal juga akan memantulkan gelombang tetapi dengan kekuatan daya yang lebih kecil dan terkadang akhirnya tidak dapat diinterpretasikan pada hasil tampilan pengolahan sinyal.

Panjang lintasan sinyal tersebut merupakan jarak antara antena hingga sinyal memantul ke antena penerima, biasa dinyatakan dengan 2 kali kedalaman objek. Maka secara lebih singkat dapat dituliskan pada Persamaan 6.

$$
h=\frac{v \Delta t}{2}
$$

Kecepatan propagasi dapat dihitung dengan menggunakan Persamaan 7.

$$
v=\frac{c}{\sqrt{\varepsilon_{r}}}
$$

$\varepsilon_{\mathrm{r}}=$ permitivitas relatif dari lapisan yang akan diukur. Ini bergantung dari material apa yang digunakan pada lapisan tersebut. c adalah kecepatan cahaya di udara.

Gambar 1 menunjukkan diagram blok dari radar penembus permukaan. Radar penembus permukaan terdiri dari antena pengirim dan penerima, unit pengumpulan data, unit tampilan, dan unit pengolahan sinyal. 
Pemfokusan Citra Radar untuk Hasil Pemodelan Radar Penembus Permukaan menggunakan Algoritma Migrasi Jarak

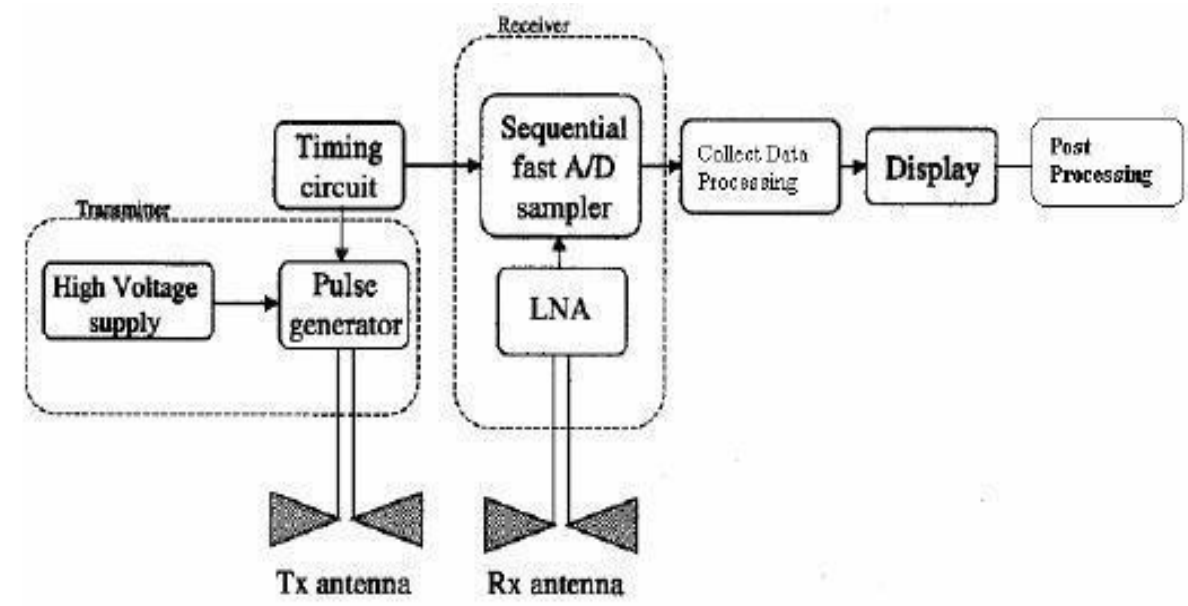

Gambar 1. Diagram Blok Radar Penembus Permukaan (Sumber: Website Departemen Pertahanan RI, 2011)

\subsubsection{Analisis Citra Radar}

Di dalam GPR, data dapat dikumpulkan dengan menggunakan tiga macam geometry scanning yang berbeda, yaitu A-scan, B-scan, C-scan (Rahman, 2010).

A-Scan merupakan pengukuran dengan cara menempatkan antena di tempat tertentu. Ini dinyatakan dengan grafik antara kekuatan sinyal dengan waktu tunda nya. Citra A-Scan untuk input impuls delta Dirac ditunjukkan pada Gambar 2.

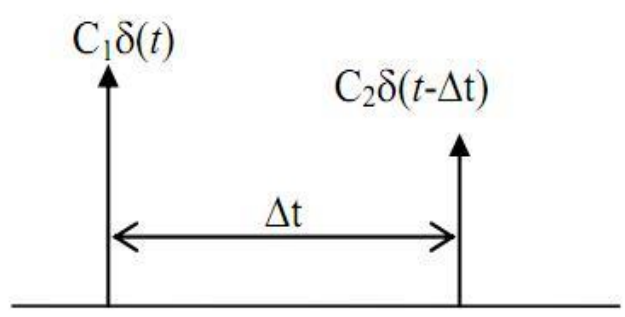

Gambar 2. A-Scan ideal dengan input impuls derta Diract (Sumber: Suksmono, 2008)

$B$-scan terdiri dari beberapa $A$-Scan. Itu berarti $B$-scan didapatkan dengan cara mengumpulkan $A$-Scan dari suatu daerah yang akan diukur pada garis horizontal. B-scan digambarkan dalam bentuk bidang datar dua dimensi antara lebar daerah yang di scan dengan waktu tunda. Hal ini digambarkan dalam bentuk hiperbola tertelungkup ditunjukkan pada Gambar 3.

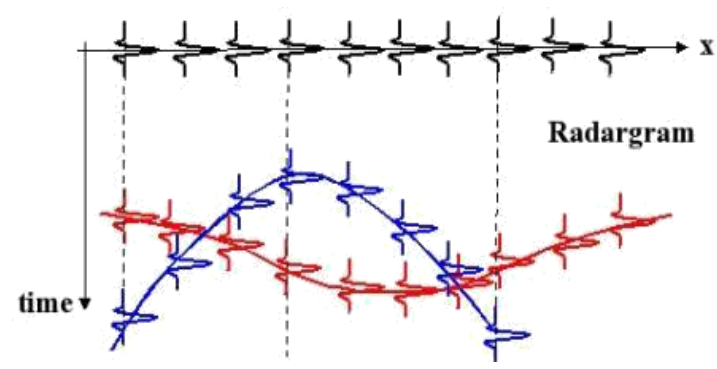

Gambar 3. Perubahan dari A-Scan ke B-scan (Sumber : Suksmono, 2008) 


\section{METODOLOGI PENELITIAN}

Metode yang digunakan pada penelitian ini adalah migrasi jarak. Algoritma migrasi jarak disebut juga SAR-based Algorithm karena algoritma ini memanfaatkan prinsip kerja dari Synthetic Aperture Radar (SAR). Algoritma ini dilakukan untuk memfokuskan citra GPR. Citra GPR 2 dimensi yang semula berbentuk kurva hiperbola kemudian difokuskan menyesuaikan dengan bentuk 2 dimensi objek yang akan dideteksi. Algoritma migrasi jarak bekerja pada domain frekuensi.

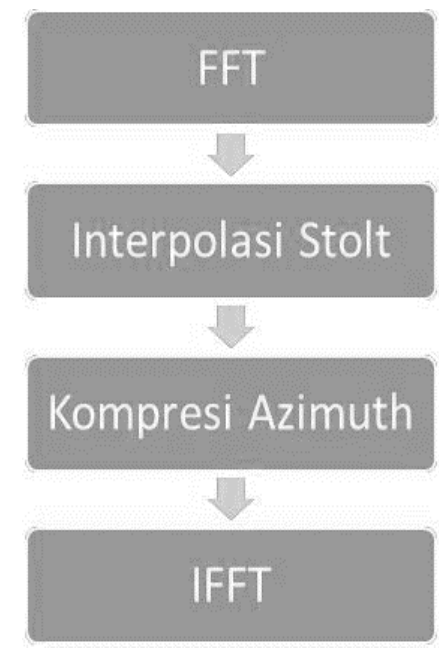

\section{Gambar 4. Blok diagram algoritma migrasi jarak}

Blok diagram pada Gambar 4 menunjukkan proses pada algoritma migrasi jarak. Secara lebih terperinci, langkah-langkah di dalam algoritma migrasi jarak adalah (Charvat, 2007):

\section{Fast Fourier Transform (FFT)}

Proses ini dilakukan untuk mengubah domain citra. Citra sebelumnya berada pada domain waktu kemudian diubah ke dalam domain frekuensi. Citra GPR 2 dimensi dinyatakan dalam bentuk $s(x, t)$ dengan $\mathrm{x}$ menyatakan lokasi objek berdasarkan arah sapuan radar dan $\mathrm{t}$ adalah waktu tempuh gelombang elektromagnetik saat ditangkap oleh antena penerima. Fast Fourier Transform (FFT) dilakukan untuk mengubah domain dari kedua dimensi citra. FFT merupakan versi kompres dari transformasi fourier diskrit. Secara umum persamaan transformasi fourier diskrit dituliskan pada Persamaan 8.

$$
X(k)=\sum_{n=0}^{N-1} x(n) e^{-i k n \frac{2 \pi}{n}} \quad 0 \leq k \leq N-1
$$

$\mathrm{x}(\mathrm{n})$ merupakan sinyal keluaran radar di dalam domain waktu dan diasumsikan berupa deretan bilangan kompleks. $\mathrm{N}$ adalah jumlah sampel frekuensi yang diinginkan. Jumlah sampel yang dicuplik akan menentukan kualitas hasil transformasi. Semakin banyak jumlah sampel yang dicuplik maka akan menghasilkan hasil yang lebih baik.

Tranformasi fourier diskrit 1 dimensi memiliki kompleksitas sebanyak $\mathrm{N}^{2}$. Ini menunjukkan operasi pada transformasi fourier diskrit 1 dimensi pada $\mathrm{N}$ sampel akan menghasilkan operasi sebanyak $\mathrm{O}\left(\mathrm{N}^{2}\right)$. Sedangkan dengan menggunakan FFT untuk mendapatkan hasil 
Pemfokusan Citra Radar untuk Hasil Pemodelan Radar Penembus Permukaan menggunakan Algoritma Migrasi Jarak

yang sama maka operasi yang dibutuhkan sebanyak $\mathrm{O}\left(\mathrm{N}{ }^{2} \log \mathrm{N}\right)$. Ini mengurangi jumlah operasi yang kemudian akan mengurang waktu komputasi yang diperlukan.

Penggunaan FFT pada algoritma migrasi jarak dinyatakan dalam Persamaan 9.

$$
s(x . t) \rightarrow s(x, \omega) \rightarrow s\left(k_{x}, \omega\right)
$$

\section{Interpolasi Stolt}

Konsep interpolasi didapatkan dari teori analisi numerik. Interpolasi didapatkan dari 2 data yang kemudian diperkirakan nilai lainnya untuk mendapatkan sejumlah data. Data hasil interpolasi akan menghaluskan kurva atau mencocokkan kurva. Ini dilakukan untuk mengurangi ambigu dari suatu jika hanya ada 2 data yang ada. Interpolasi yang digunakan bisa bermacam-macam, diantaranya adalah interpolasi linier, spline, dan lain-lain.

Interpolasi Stolt merupakan tahapan penting di dalam algoritma ini. Interpolasi Stolt biasa juga disebut pemetaan Stolt. Interpolasi Stolt memanfaatkan versi spasial dari frekuensi yaitu bilangan gelombang atau yang biasa dilambangkan dengan k. Prinsipnya adalah dengan memetakan nilai $\omega$ yang berada pada domain frekuensi menjadi $k_{\text {.. }}$ yang berada pada domain spasial frekuensi. Interpolasi ini dilakukan 1 dimensi pada sumbu yang searah dengan sapuan radar. Prinsip ini dituliskan pada persamaan 10.

$$
s\left(k_{x}, \omega(t)\right) \rightarrow s\left(k_{x}, k_{y}\right)
$$

Hal yang terpenting di dalam interpolasi Stolt bahwa panjang gelombang untuk azimuth dan range merupakan hasil langsung dari panjang gelombang radar (Rahman, 2010). Gambar 6 menunjukkan konsep panjang gelombang dalam sinyal SAR. $\lambda r$ berhubungan dengan ground range. $\theta$ adalah sudut kemiringan dari SAR. $\lambda x$ berhubungan dengan sumbu spasial dari variabel $x$. Hal ini ditunjukkan pada Gambar 5.
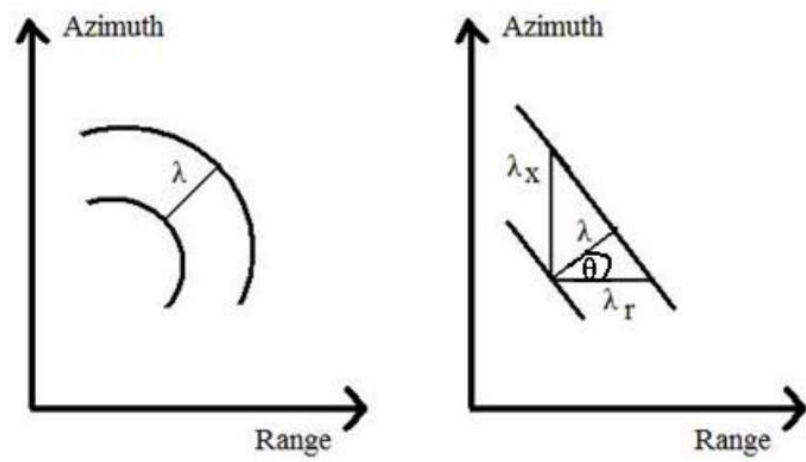

\section{Gambar 5. Pola Radiasi Antena Radar dan Perkiraan Garis Lurus dalam suatu Area (Sumber: Rahman, 2010)}

Berdasarkan penurunan rumus panjang gelombang dan frekuensi sudut, maka interpolasi Stolt untuk memetakan frekuensi $(\omega)$ ke bilangan gelombang kr dapat digunakan Persamaan 11 (Ozdemir dkk, 2014).

$$
k_{x}^{2}+k_{y}^{2}=\left(\frac{2 \omega}{c}\right)^{2} \rightarrow \omega=\frac{c}{2} \sqrt{k_{x}^{2}+k_{y}^{2}}
$$


Interpolasi Stolt menggunakan persamaan ini untuk melakukan pemetaan frekuensi $(\omega)$ ke bilangan gelombang $\mathrm{k}_{\mathrm{r}}$.

Selanjutnya untuk memetakan $\mathrm{k}_{\mathrm{r}}$ ke $\mathrm{k}_{\mathrm{y}}$ akan digunakan persamaan phytagoras dengan hubungan yang dituliskan pada Persamaan 12 dan 13.

$$
\begin{gathered}
k_{x}{ }^{2}+{k_{y}}^{2}=k_{r}{ }^{2} \\
k_{y}=\sqrt{{k_{r}}^{2}+k_{x}{ }^{2}}
\end{gathered}
$$

\section{Kompresi Azimuth}

Kompresi azimuth dilakukan untuk memfokuskan citra pada sumbu azimuth. Prinsipnya seperti match filtering dengan cara mengalikan sinyal dengan sinyal awal yang dipancarkan oleh radar (Ozdemir dkk, 2014). Hal ini ditunjukkan pada Persamaan 14.

$$
S_{m f}\left(k_{x}, k_{y}\right) \rightarrow s\left(k_{x}, k_{y}\right)
$$

dimana $S_{m f}$ merupakan sinyal referensi.

\section{Inverse Fast Fourier Transform}

Pada tahap ini dilakukan perubahan domain citra. Citra pada domain spasial frekuensi diubah ke domain waktu untuk menujukkan objek yang dideteksi. Tahap ini dilakukan dengan proses Inverse Fast Fourier Transform (IFFT).

Persamaan umumnya dituliskan pada Persamaan 15.

$$
x(n)=\frac{1}{N} \sum_{n=0}^{N-1} X(k) e^{-i k n \frac{2 \pi}{n}} \quad 0 \leq n \leq N-1
$$

Proses ini dilakukan pada kedua sumbu. Hal ini dituliskan pada Persamaan 16.

$$
S_{m f}\left(k_{x}, k_{y}\right) \rightarrow s(X, Y)
$$

\section{HASIL DAN PEMBAHASAN}

Penelitian dilakukan dengan perangkat lunak GPRMaxV2.0 dan dilakukan dalam bidang 2 dimensi. Parameter yang diperlukan untuk pemodelan diatur.

Dalam penelitian kali ini, dilakukan beberapa skenario penelitian. Skenario penelitian pada kondisi yang berbeda-beda tetapi dengan medium yang sama, yaitu medium pasir dan objek yang berbentuk silinder berongga.

Parameter umum yang sama untuk semua skenario adalah frekuensi kerja sinyal $=3 \mathrm{GHz}$ dan bandwith sinyal $=2 \mathrm{GHz}$ 
Pemfokusan Citra Radar untuk Hasil Pemodelan Radar Penembus Permukaan menggunakan Algoritma Migrasi Jarak

Ada 3 skenario yang dilakukan. Untuk skenario 1 digunakan 1 objek, untuk skenario 2 digunakan 2 objek, dan untuk skenario 3 digunakan 3 objek.

\subsection{Skenario 1}

Objek terletak pada kedalaman $0.50 \mathrm{~m}$ dengan posisi $\mathrm{x}$ pada $60 \mathrm{~cm}$. Pemodelan GPR dilakukan untuk objek yang berbentuk silinder dengan diameter $5 \mathrm{~cm}$. Dilakukan sebanyak 80 kali iterasi dengan pergeseran antena setiap $1 \mathrm{~cm}$. Pemodelan secara geometri dalam koordinat kartesian ditunjukkan pada Gambar 6.

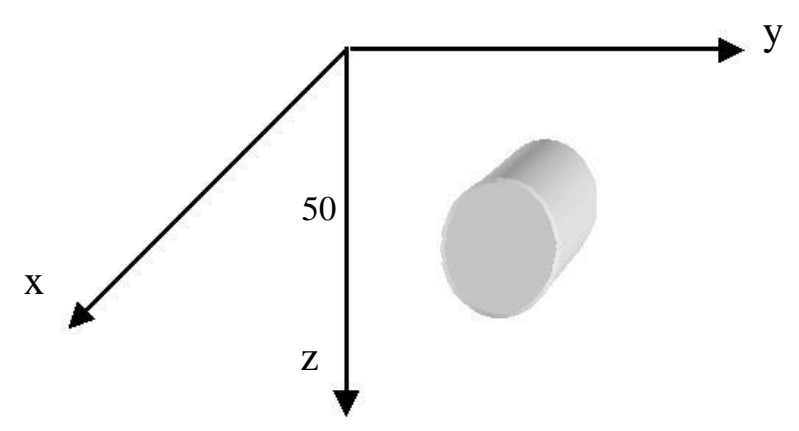

Gambar 6. Geometri skenario 1 objek

\subsubsection{Hasil dan Pembahasan Skenario 1}

Sinyal keluaran GPR diolah menjadi citra B-scan yang berbentuk hiperbola. Citra ini difokuskan dengan algoritma migrasi jarak sehingga menjadi bentuk hampir menyerupai titik yang lebih jelas menunjukkan posisi objek yang sebenarnya. Hasil skenario 1 objek ditunjukkan pada Gambar 7 dan Tabel 1.

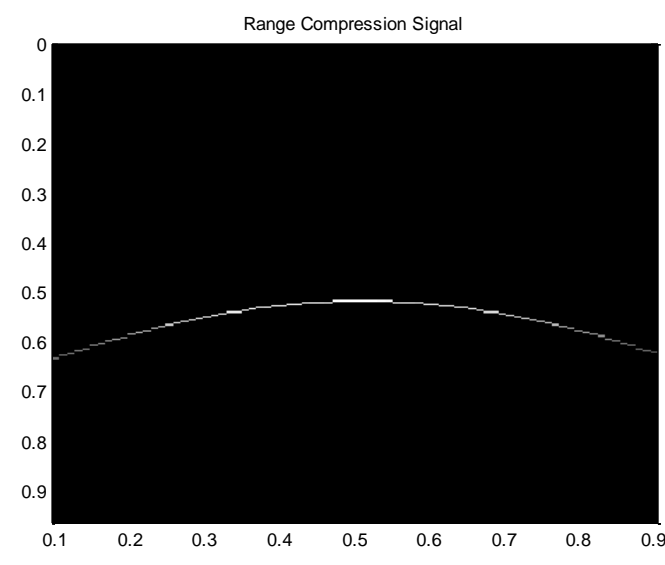

(a)

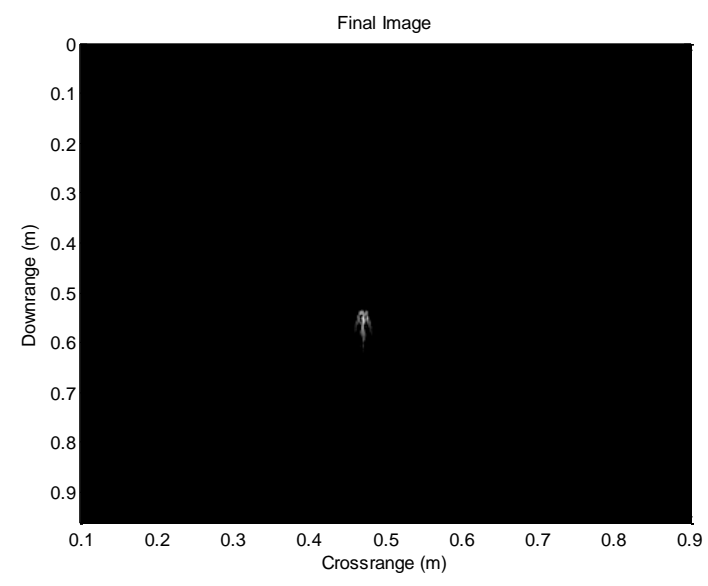

(b)

\section{Gambar 7. Hasil simulasi skenario 1 objek (a) B-scan; (b) hasil algoritma migrasi jarak}

Posisi objek yang terdeteksi menunjukkan hasil yang hampir bersesuaian dengan desain awal walaupun posisi objek yang kedua sedikit berbeda. Untuk posisi yang lebih rinci ada pada Tabel 1 . B-scan dari skenario 1 objek menunjukkan adanya 1 kurva hiperbola. Kurva ini menunjukkan adanya 1 objek yang terdeteksi. 
Tabel 1. Posisi skenario 1 objek

\begin{tabular}{|c|c|c|c|}
\hline \multicolumn{2}{|c|}{ Posisi objek desain awal } & \multicolumn{2}{c|}{ Posisi objek hasil simulasi } \\
\hline $\begin{array}{c}\text { Crossrange }(\mathrm{m}) \\
\text { sumbu x }\end{array}$ & $\begin{array}{c}\text { Downrange }(\mathrm{m}) \\
\text { sumbu y }\end{array}$ & $\begin{array}{c}\text { Crossrange }(\mathrm{m}) \\
\text { sumbu x }\end{array}$ & $\begin{array}{c}\text { Downrange }(\mathrm{m}) \\
\text { sumbu y }\end{array}$ \\
\hline 0.5 & 0.5 & 0.4786 & 0.5085 \\
\hline
\end{tabular}

Berdasarkan Tabel 1, posisi objek yang terdeteksi berbeda dari posisi awal yang direncanakan. Persentase kesalahan untuk posisi x sebesar $4 \%$ dan untuk posisi y sebesar 2 $\%$.

\subsection{Skenario 2}

Pemodelan GPR dilakukan untuk objek yang berbentuk silinder berongga dengan diameter 5 $\mathrm{cm}$. Ada 2 objek yang digunakan. Objek terletak pada kedalaman $20 \mathrm{~cm}$ dan $50 \mathrm{~cm}$ dengan diameter yang sama. Posisi x objek 1 pada $40 \mathrm{~cm}$ dan posisi x objek 2 pada $60 \mathrm{~cm}$. Pemodelan dilakukan sebanyak 80 kali iterasi dengan pergeseran antena setiap $1 \mathrm{~cm}$. Secara geometri ditunjukkan pada Gambar 8.

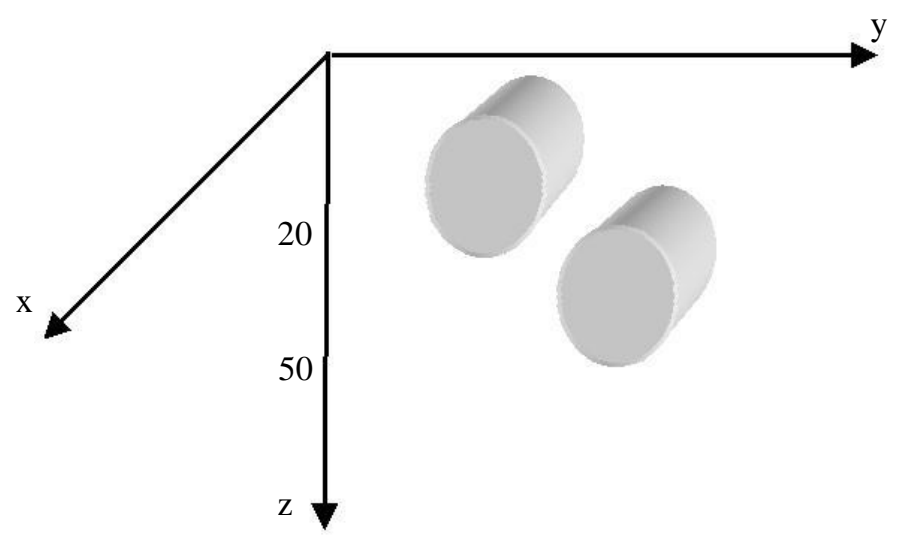

Gambar 8. Geometri skenario 2 objek

\subsubsection{Hasil dan Pembahasan Skenario 2}

Penelitian dilakukan untuk 2 objek yang bentuknya sama. Hasil skenario 2 objek ditunjukkan pada Gambar 9 dan Tabel 2. Gambar 9 menunjukkan adanya 2 titik yang terdeteksi sebagai objek yang diamati. Ini sesuai dengan skenario di awal.

Posisi objek yang terdeteksi menunjukkan hasil yang hampir bersesuaian dengan desain awal walaupun posisi objek yang kedua sedikit berbeda. Untuk posisi yang lebih rinci ada pada Tabel 2. 
Pemfokusan Citra Radar untuk Hasil Pemodelan Radar Penembus Permukaan menggunakan Algoritma Migrasi Jarak

Tabel 2 Posisi skenario 2 objek

\begin{tabular}{|c|c|c|c|c|c|c|c|}
\hline \multicolumn{4}{|c|}{ Posisi objek 1 } & \multicolumn{4}{c|}{ Posisi objek 2 } \\
\hline \multicolumn{2}{|c|}{ Desain awal } & \multicolumn{2}{|c|}{ Hasil simulasi } & \multicolumn{2}{c|}{ Desain awal } & \multicolumn{2}{c|}{ Hasil Simulasi } \\
\hline Sb $\times(\mathrm{m})$ & Sb y $(\mathrm{m})$ & Sb x (m) & Sb y $(\mathrm{m})$ & Sb x (m) & Sb y $(\mathrm{m})$ & Sb x (m) & Sb y (m) \\
\hline 0.7 & 0.2 & 0.486 & 0.1923 & 0.5 & 0.5 & 0.4799 & 0.5144 \\
\hline
\end{tabular}

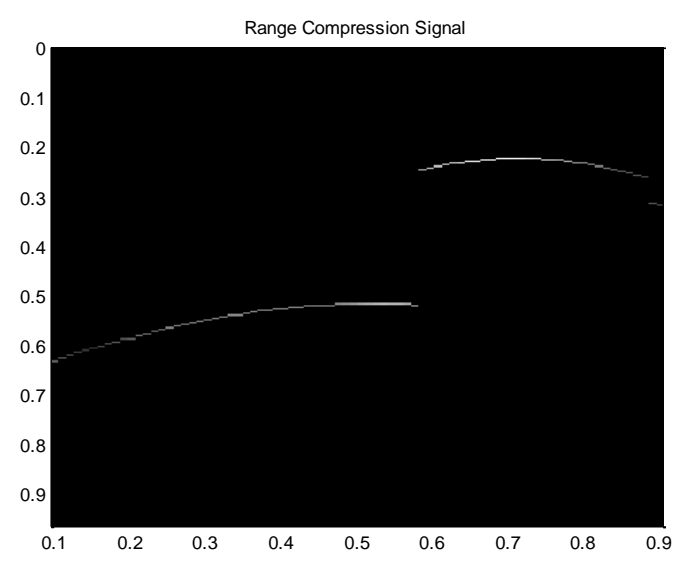

(a)

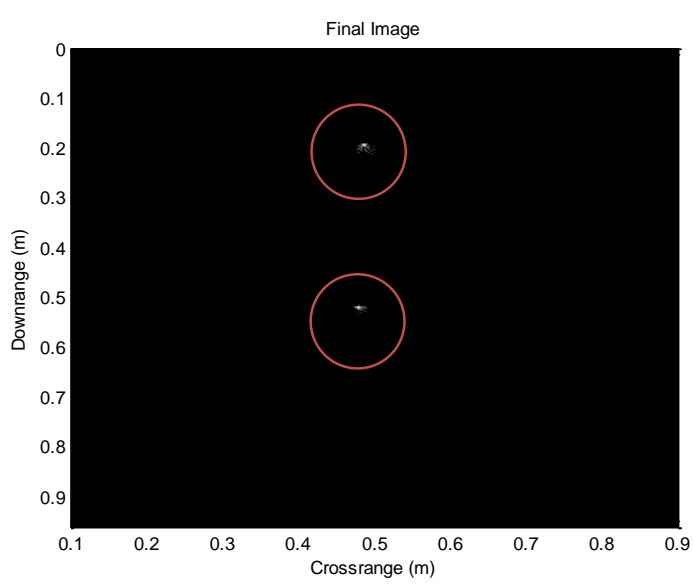

(b)

\section{Gambar 9. Hasil simulasi skenario 2 objek (a) B-scan; (b) hasil algoritma migrasi jarak}

Perbedaan ini dapat dilihat juga pada hasil $B$-scan yang merupakan keluaran dari hasil modelling GPR sehingga menyebabkan hasil pengolahan dengan algoritma migrasi jarak pun menjadi sedikit berbeda. Ini disebabkan adanya distorsi dari hasil simulasi. Hasil $B$-scan menunjukkan hiperbola yang kurang sempurna dari objek yang kedua. Hiperbola objek kedua sedikit terpotong. Adanya objek pertama yang berada di atasnya kemungkinan menyebabkan posisi objek kedua yang terdeteksi sedikit berbeda.

Pantulan objek kedua tertutupi oleh pantulan objek pertama yang ada diatasnya. Objek pertama dan kedua memiliki diameter dan posisi crossrange yang sama sehingga menyebabkan pada posisi waktu dan scan tertentu pantulan objek kedua tidak tertangkap oleh penerima. Pantulan objek kedua memiliki waktu tunda yang lebih besar. Hiperbola yang kurang sempurna dan waktu tunda yang lebih besar menyebabkan posisi kedalaman yang terdeteksi dari hasil keluaran pengembangan algoritma migrasi jarak sedikit berbeda dari skenario di awal.

Berdasarkan Tabel 2, persentase kesalahan untuk setiap posisi dibandingkan dengan yang direncanakan di awal untuk posisi x sebesar $17 \%$ dan untuk posisi y sebesar $3 \%$.

\subsection{Skenario 3}

Dilakukan pemodelan GPR untuk objek yang berbentuk bola dengan diameter $5 \mathrm{~cm}$. Ada 3 objek yang digunakan. Objek terletak pada kedalaman $20 \mathrm{~cm}, 50 \mathrm{~cm}$, dan $70 \mathrm{~cm}$. Penelitian ini dilakukan sebanyak 80 kali iterasi dengan pergeseran antena setiap $1 \mathrm{~cm}$. Pemodelan skenario penelitian pada koordinat kartesian ditunjukkan pada Gambar 10. 


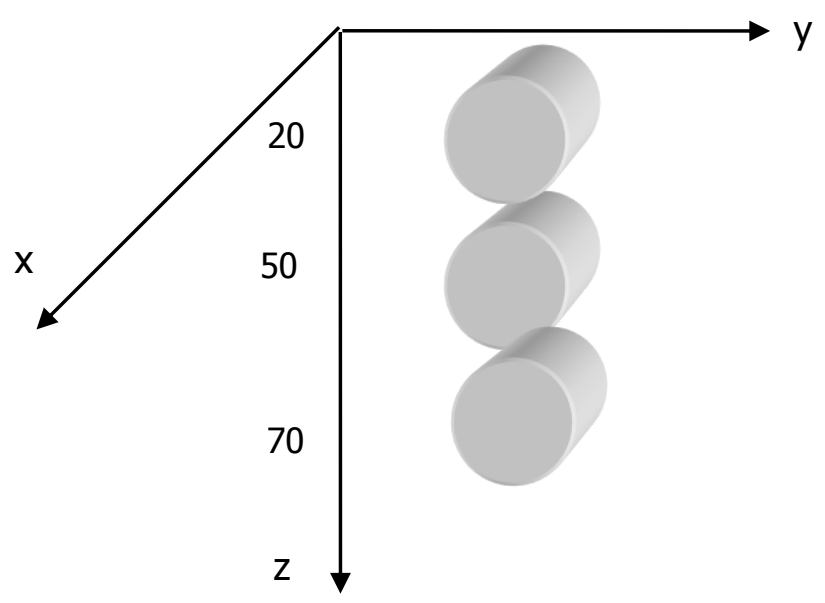

Gambar 10. Geometri dari skenario 3 objek

\subsubsection{Hasil dan Pembahasan Skenario 3}

Penelitian dilakukan untuk 3 objek yang bentuknya sama. Objek diletakkan pada kedalaman yang berbeda-beda. Hasil skenario 3 objek ditunjukkan pada Gambar 11 dan Tabel 3.

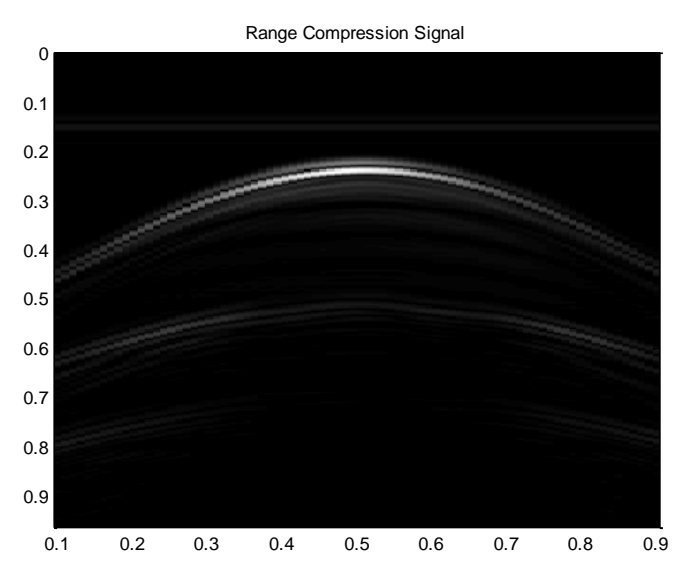

(a)

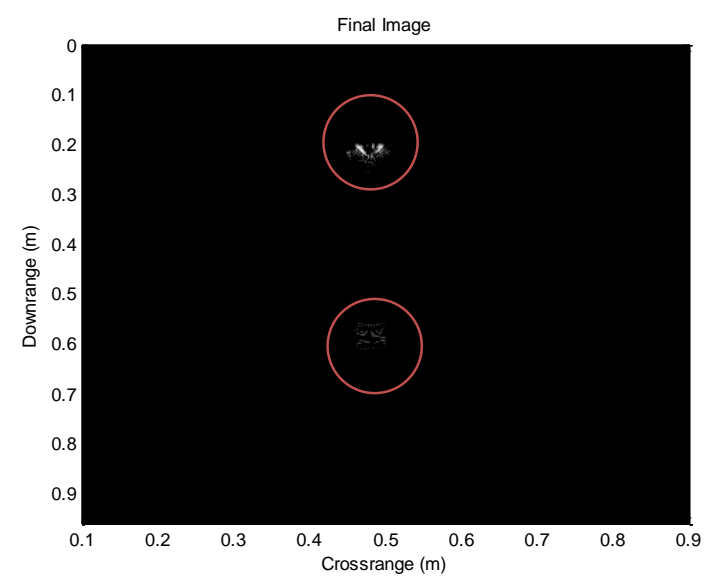

(b)

\section{Gambar 11. Hasil simulasi skenario 3 objek (a) B-scan; (b) hasil algoritma migrasi jarak}

Pada simulasi ini, citra yang terlihat hanya mendeteksi adanya 2 objek. Objek ketiga yang kedalamannya paling dalam tidak dapat terdeteksi dengan baik. Objek kedua pun terlihat sedikit samar, tidak terlalu jelas. Objek ketiga tidak terlihat pada hasil B-scan juga. Posisi lebih rinci ditunjukkan pada Tabel 3.

Kedalaman objek ketiga yang semakin dalam membuat pantulannya semakin lemah. Kemudian, objek ketiga 'tertutupi' oleh dua objek yang ada di atasnya yang memiliki ukuran yang sama dan posisi crossrange yang sama sehingga pantulan dari objek ketiga yang lemah tadi tidak dapat ditangkap dengan baik oleh penerima. 
Pemfokusan Citra Radar untuk Hasil Pemodelan Radar Penembus Permukaan menggunakan Algoritma Migrasi Jarak

Tabel 3. Posisi skenario 3 objek

\begin{tabular}{|c|c|c|c|}
\hline \multicolumn{4}{|c|}{ Posisi objek 1} \\
\hline \multicolumn{2}{|c|}{ Desain awal } & \multicolumn{2}{|c|}{ Hasil simulasi } \\
\hline $\mathrm{Sb} \times(\mathrm{m})$ & $\begin{array}{l}\text { Sb y } \\
\text { (m) }\end{array}$ & $\mathrm{Sb} \times(\mathrm{m})$ & Sb y $(m)$ \\
\hline 0.5 & 0.2 & 0.4785 & 0.2155 \\
\hline \multicolumn{4}{|c|}{ Posisi objek 2} \\
\hline \multicolumn{2}{|c|}{ Desain awal } & \multicolumn{2}{|c|}{ Hasil Simulasi } \\
\hline $\mathrm{Sb} \times(\mathrm{m})$ & $\begin{array}{c}\text { Sb y } \\
\text { (m) }\end{array}$ & $\mathrm{Sb} \times(\mathrm{m})$ & Sb y $(m)$ \\
\hline 0.5 & 0.5 & 0.5025 & 0.5031 \\
\hline \multicolumn{4}{|c|}{ Posisi objek 3} \\
\hline \multicolumn{2}{|c|}{ Desain awal } & \multicolumn{2}{|c|}{ Hasil simulasi } \\
\hline $\mathrm{Sb} \times(\mathrm{m})$ & $\begin{array}{c}\mathrm{Sby} \\
\text { (m) }\end{array}$ & $\mathrm{Sb} \times(\mathrm{m})$ & Sb y $(m)$ \\
\hline 0.5 & 0.7 & - & - \\
\hline
\end{tabular}

Berdasarkan Tabel 3, persentase kesalahan untuk setiap posisi dibandingkan dengan yang direncanakan di awal untuk posisi x sebesar $4 \%$ dan untuk posisi y sebesar $8 \%$. Persentase kesalahan ini hanya dihitung berdasarkan posisi objek 1 dan 2. Posisi objek 3 tidak dapat dihitung karena tidak terlihat pada hasil $B$-scan.

\section{KESIMPULAN}

Adapun kesimpulan dari penelitian ini adalah sebagai berikut :

1. Algoritma migrasi jarak merupakan salah satu algoritma yang efektif digunakan untuk melakukan migrasi data GPR sehingga menghasilkan citra yang lebih fokus dengan resolusi yang baik tanpa menambah lebar pita. Pemfokusan bisa dilakukan dengan waktu komputasi yang relatif cepat.

2. Berdasarkan penelitian yang sudah dilakukan, pengolahan sinyal dari skenario 1 objek dan 2 objek menunjukkan jumlah objek yang terdeteksi sesuai dengan yang dirancang di awal. Pengolahan sinyal dari skenario 1 dan 2 menunjukkan posisi kedalaman objek hampir sesuai dengan yang dirancang di awal dengan perbedaan \pm $3 \mathrm{~cm}$.

3. Persentase kesalahan untuk posisi $x$ pada skenario 1 objek sebesar $\pm 4 \%$ dan untuk posisi y sebesar $\pm 2 \%$.

4. Persentase kesalahan untuk posisi $x$ pada skenario 2 objek sebesar $\pm 17 \%$ dan untuk posisi y sebesar $\pm 3 \%$.

5. Persentase kesalahan untuk posisi $x$ pada skenario 3 objek sebesar $\pm 4 \%$ dan untuk posisi y sebesar $\pm 8 \%$ hanya untuk objek 1 dan 2 . 
6. Pada skenario 3 objek, objek ketiga tidak dapat terdeteksi. Hal ini disebabkan oleh pantulan yang dihasilkan dari objek ketiga lemah. Kurva hiperbola dari objek ketiga pada hasil $B$-scan juga tidak terlihat dengan jelas sehingga untuk migrasi selanjutnya dengan menggunakan algoritma migrasi jarak pun tidak memberikan hasil yang benar. Hasil $B$-scan yang baik akan menghasilkan citra yang lebih mendekati kepada desain skenario di awal setelah diolah dengan algoritma migrasi jarak.

\section{DAFTAR RUJUKAN}

Miller, K. (2005). Modelling of GPR Wave Propagation and Scattering in Inhomogeneous Media. Oslo: Master Thesis.

Cumming, G Ian and Wong, Frank H. (2005) Digital Processing of Synthetic Aperture Radar Data. USA: Artech House.

Ozdemir, Caner dkk. (2014). Migration Methods in B-scan Ground Penetrating Radar Imaging: A Review. Mersin: Mersin University.

Charvat, Gregory Louis. (2007). A Low-Power Radar Imaging System, 2nd edition. Michigan: Michigan State University. PhD Thesis.

Suksmono, A.B. (2008). Memahami Penginderaan Kompresif dengan Matlab. Bandung: STEI Institut Teknologi Bandung.

Tim. (2011). Defense Department RI website. [Online]. Diakses pada tanggal 10 Oktober 2014 dari http://buletinlitbang.dephan.go.id/index.asp?vnomor=23\&mnorutisi=8

Rahman, Samiur. (2010). Focusing Moving Targets using Range Migration Algorithm in Ultra Wideband Low Frequency Synthetic Aperture Radar. Swedia: Master Thesis.

Azizah, dkk. (2011). 3-Dimensional Analysis of Ground Penetrating Radar Image for NonDestructive Road Inspection. Bandung: International Conference on Instrumentation, Communication, Information Technology and Biomedical Engineering. 